\title{
News and Events
}

INTA Congress: The City as a catalyst for Growth International Urban Development Association 22nd Annual Congress

24-29 May 1998, Taipei \& Kaosuing, Taiwan

Information: no contact name available

Tel: +31703244526 . Fax: +31703280727

Urban Design Group Study Tour

June 1998, Cities of the Plain of Lombardy and Veneto

Information: Alan Stones, Fullerthorne, Church Street, Kelvedon, Essex, CO5 9AH

Tel: $+44(0) 1245437642$.

Local and Regional Sustainable Human Development from the Gender Perspective: Conference

10-12 June 1998, Aulanko Congress Centre, Finland
Information: Liisa Horelli

Tel: +3589684 8867. Email: liisa.Horelli@hut.fi

Royal Australian Planning Institute 26th Conference

6-9 July 1998, Brisbane Convention and Exhibition Centre, Australia

Email: mcarey@ozemail.com.au

8th International Planning Conference

15-18 July 1998, University of NSW, Sydney, Australia

Information: no contact name available

Tel: +61293854836 . Fax: +61293856264

IV International Conference on Urban History: The European City: Places and Institutions

3-5 September 1998, Venice

Information: no contact details 